\title{
Many young men with prostate-specific antigen (PSA) screen- detected prostate cancers may be candidates for active surveillance
}

\author{
Jeri Kim ${ }^{\star}$, James Ebertowski ${ }^{\star \star}$, Matthew Janiga\#, Jorge Arzola\#\#, Gayle Gillespie ${ }^{\# \#}$, Michael \\ Fountain $^{\S}$, Douglas SoderdahI ${ }^{* *}$, Edith Canby-Hagino ${ }^{\star *}$, Sally Elsamanoudi ${ }^{\Uparrow}$, Jennifer \\ Gurski ${ }^{\Uparrow \uparrow}$, John W. Davis ${ }^{\square}$, Patricia A. Parker ${ }^{\square}$, and Douglas D. Boyd ${ }^{\square \square}$ \\ "Department of Genitourinary Medical Oncology, The University of Texas MD Anderson Cancer \\ Center, Houston, TX \\ ${ }^{* *}$ San Antonio Military Medical Center, San Antonio, TX \\ \#60th Medical Group, David Grant USAF Medical Center, Travis AFB, CA \\ \#\#8th Medical Group, Wright-Patterson Medical Center, Wright-Patterson AFB, OH \\ \$96th Medical Group, Eglin Regional Hospital, Eglin AFB, FL \\ "Center for Prostate Disease Research, Walter Reed National Military Medical Center, Bethesda, \\ MD \\ ฯฯ Womack Army Medical Center, Fort Bragg, NC \\ Department of Urology, Cancer Biology, The University of Texas MD Anderson Cancer Center, \\ Houston, TX, USA \\ Department of Behavioral Sciences The University of Texas MD Anderson Cancer Center, \\ Houston, TX, USA
}

\section{SUMMARY}

Objective-To identify a population of young men (aged $<55$ years at diagnosis) with very-lowrisk prostate cancer (stage cT1c, with prostate-specific antigen [PSA] density of $<0.15 \mathrm{ng} / \mathrm{mL} / \mathrm{g}$, Gleason score $\leq 6$, and $\leq 2$ positive biopsy cores with $<50 \%$ tumour involvement) that may be candidates for active surveillance (AS).

Patients and methods-We queried a Department of Defense tumor registry and hard-copy records for servicemen diagnosed with prostate cancer from 1987 to 2010.

Statistical analyses were undertaken using Fisher's exact and chi-square testing.

Results-From 1987-1991 and 2007-2010, PSA screen-detected tumours diagnosed in men aged $\leq 55$ years $>30$-fold.

Data for a subset of men (174) with PSA screen-detected cancer were evaluable for disease risk assessment.

Of the 174 men with screen-detected disease, 81 (47\%) had very-low-risk disease.

Correspondence: Douglas Boyd, Department of Cancer Biology, Unit 173, The University of Texas MD Anderson Cancer Center, 1515 Holcombe Blvd., Houston, TX 77030, USA. dboyd@ mdanderson.org.

Disclaimer

The views expressed are those of the authors and do not reflect the official policy or position of the DoD or the USA Government. 
Of that group, 96\% (78/81) selected treatment and, of 57 men undergoing radical prostatectomy (RP), the tumours of $49(86 \%)$ carried favourable pathology (organ confined, $<10 \%$ gland involvement, Gleason $\leq 6$ ).

Conclusions-Nearly half of young men with PSA screen-detected prostate cancer are AS candidates but the overwhelming majority seek treatment.

Considering that many tumours show favourable pathology at RP, there is a possibility that these patients may benefit from AS management.

\section{Keywords}

very-low-risk prostatic neoplasms; active surveillance; risk assessment; overtreatment

\section{Introduction}

The widespread adoption of PSA screening since the late 1980s [1], coupled with the move to extended prostate biopsies, has substantially increased early detection of prostate cancer, spurring an increase in localised treatment when there is a perceived chance of cure. Indeed, prostate cancer mortality rates have decreased 30-40\% since 1990 [2] and continue to decline.

However, there has been vigorous debate as to whether PSA screening also leads to the detection (and possibly overtreatment) of a subset of tumours that would have remained asymptomatic over the patient's lifetime if it were not for screening. Indeed, several lines of evidence support this notion. First, although 30-50\% of men aged $>50$ years asymptomatic for prostate cancer harbour disease at autopsy, only $10 \%$ of men develop clinically evident prostate cancer over their lifetime [3]. Second, if PSA screening were merely detecting asymptomatic cancers that were all destined to become clinically evident, the total number of individuals diagnosed with disease should be unaffected by screening. Instead, current overall prostate cancer incidence rates are $60 \%$ higher than they were during the pre-PSA screening era for the general population (http://seer.cancer.gov). This increased incidence rate is unlikely a consequence of the initial spike in diagnosis, considering the 5- to 12-year earlier diagnosis provided by PSA screening [4] and that $>20$ years have elapsed since the widespread adoption of screening [1].

For young men (arbitrarily defined as those aged $\leq 55$ years at diagnosis), prostate cancer diagnosis rates have increased sevenfold over 20 years [5], with no sign of abating. Moreover, most of these men are treated with radical prostatectomy (RP) or radiation [6,7]. Unfortunately, such treatment is often associated with decrements [8] in the quality of life (fertility loss, erectile dysfunction, urinary or bowel incontinence), although these sideeffects may depend on the experience of the surgeon, among other factors [9]. Notably, these treatment-related problems are even more pertinent to youthful patients, gainfully employed and physically (especially those engaged in manual labour) and sexually active.

An alternative to immediate therapy, active surveillance (AS) is a management approach in which men are regularly tested for disease progression, and only those subsequently thought to be at risk for progression are treated. Cure likelihood is probably not reduced by deferred treatment [10]. The criteria for choosing AS for young men need to be stringent (stage cT1c, Gleason score $\leq 6$ [no pattern 4], $\leq 2$ positive biopsy cores with $<50 \%$ tumour involvement per core, and a PSA density of $<0.15 \mathrm{ng} / \mathrm{mL} / \mathrm{g}$ ) [3,11], and patients must understand that AS may mean delayed, not avoided treatment. AS boasts some potential advantages. First, treatment is offered at diagnosis only to men most likely to benefit, reducing health costs [12] and sparing those who can forgo therapy. Second, AS has been associated with greater 
quality-adjusted life expectancy than occurs after RP [13]. Indeed, even if AS only provides for delayed (rather than avoided) treatment, it would at least allow for normal erectile and voiding functions in the interim thereby preserving quality of life for young men opting for this management approach.

To date, there have been no studies among young men to identify a candidate population for AS. Accordingly, the objective of the present retrospective study of men aged $\leq 55$ years with a prostate cancer diagnosis was to identify a potential candidate cohort for AS. We elected to use Department of Defence (DoD) servicemen as our study population for several reasons. First, the DoD tracks cancer by using the Automated Central Tumor Registry (ACTUR), its centralised database established in 1986. ACTUR allows access to case histories of patients seen at multiple military treatment facilities (MTFs), thereby removing geographic biases with respect to management. Second, annual and retirement physical examinations (93\% of DoD servicemen retire by the age of 50 years) are mandatory for all personnel, and this heightened vigilance probably increases PSA screening and disease detection, compared with screening in the general population. Our earlier study [14] argued against the possibility that this elevated prostate cancer rate resulted from occupational factors. Third, the argument that financial considerations and medicolegal issues bias physicians toward aggressive management of even very-low-risk disease is not pertinent to the Armed Forces, in which there is no case-volume reimbursement, and litigation by servicemen is prohibited. Last, decision-making by DoD servicemen with prostate cancer more likely resembles that of the general population, most of whom are treated at community facilities rather than that at large academic centres: at community facilities, patients typically consult with a urologist, as do their counterparts treated at most of the MTFs used in the present study. In contrast, patients treated at large academic centres confer with urologists, genitourinary medical oncologists, and radiation oncologists about treatment options. This difference is important because prior studies have shown a strong relationship between type of specialist seen and treatment choice [15].

\section{Patients and methods}

We queried the ACTUR database to identify our population of men with prostate cancer among Armed Forces personnel during the period 1987-2010. We then sub-queried it for patients aged $\leq 55$ years. ACTUR's unique identifiers were used to eliminate duplication of records.

PSA screen-detected disease was defined as clinical stage T1c. We used the Epstein criteria (stage cT1c, PSA density of $<0.15 \mathrm{ng} / \mathrm{mL} / \mathrm{g}$, Gleason score $<6$ [no pattern 4], $<2$ positive biopsy cores with $<50 \%$ tumour involvement) to classify very-low-risk disease [3]. Patients (very low risk and all others) were included only if the fields corresponding to those criteria contained data.

As most of the RP pathology reports stated the percentage of prostate gland involvement rather than the dominant tumour size, we used the criteria of Resnick et al. [16] to define favourable pathology (prostate-confined disease, Gleason $<6$ [no pattern 4] and $<10 \%$ gland involvement). We obtained Institutional Review Board approvals from all participating institutions.

Statistical analyses were performed using Fisher's exact and chi-square testing and Prism v5.01 software (GraphPad). 


\section{Results}

\section{Increased incidence of PSA screen-detected prostate cancer after adoption of required annual physical examinations}

Considering the heightened vigilance associated with mandatory annual physical examinations required since the early-mid 1990s, we hypothesised that the fraction of PSA screen-detected prostate cancer has increased over time and that a subset represents verylow-risk disease, thus providing a candidate cohort for AS. Accordingly, we queried the DoD tumour registry (ACTUR) for prostate cancer diagnosed in men aged $\leq 55$ years and for the fraction corresponding to PSA screen-detected disease (i.e. cT1c) over the 19872010 period (Figure 1). Among men diagnosed with prostate cancer between 1987-1991 and before the requirement for annual physical examinations, the rate of PSA screen-detected disease was low (2\%, five of 251 cases). However, statistically significant increases to $16 \%$ $(114 / 669)(P<0.001)$ and then to 45\% (597/1230) $(P<0.001)$ during the $1992-1996$ and 1997-2001 periods, respectively, were evident spanning and after adoption of the programme. This rate of increase slowed for the 2002-2006 period (56\%, 931/1676 cases), although the difference was statistically significant relative to the 1997-2001 period. Thereafter, the increase in PSA screen-detected disease (57\%, 671/1181 cases for 20072010) was modest and not statistically significantly different relative to the previous period (Figure 1).

\section{Incidence of very-low-risk prostate cancer among screen-detected cases in men aged $\leq 55$ years}

As some of the parameters used to define very-low-risk disease were not tracked by ACTUR until recently, we could only classify by risk a subset (174) of the PSA screen-detected tumours (Figure 1). Population characteristics for these 174 cases diagnosed at the age of $\leq$ 55 years are described in Table 1 . This cohort was well distributed across the 10 geographically dispersed MTFs in our study: Texas, North Carolina, Washington DC, Virginia, Hawaii, Florida, Maryland, Washington, Ohio, and California. The men's mean (range) age was 49.8 (36-55) years. Most of the men were White (57\%); African-Americans and 'Other' racial groups constituted $34 \%$ and $9 \%$ of the population, respectively. Both the mean and median number of total biopsy cores taken were 12 ranging from 3-26. The biopsy findings strongly favoured low-volume, low-grade disease: the median number of positive cores was 2, >95\% of tumour biopsies had Gleason scores $\leq 6$, and $56 \%$ of the cores had $<10 \%$ tumour involvement. The median (range) PSA density was $0.13(0.02-0.91) \mathrm{ng} /$ $\mathrm{mL} / \mathrm{g}$.

Of the 174 cases of PSA screen-detected disease evaluable for risk classification, $47 \%$ of the tumours met our definition of very low risk (i.e., cT1C, biopsy Gleason $\leq 6$ [no pattern 4], PSA density of $<0.15 \mathrm{ng} / \mathrm{mL} / \mathrm{g}$, and $\_$positive biopsy cores of an extended set with $<50 \%$ tumour involvement in any core). A diagnosis of very-low-risk disease was more likely for men aged $<49$ years $(P=0.004)$ but was not correlated with race $(P=0.93)$ or family history of cancer $(P=0.374)$. The remaining 93 cases $(53 \%)$ were aggregated as 'Others' on the basis of their not fulfilling one or more of the criteria used to define very-low-risk prostate cancers.

\section{Incidence and implications of curative therapy decisions among men aged $\leq \mathbf{5 5}$ years diagnosed with very-low-risk prostate cancer}

Among the 81 men with very-low-risk disease, 78 (96\%) selected curative therapy by RP or a radiation technique, all within 4 months of diagnosis. The latter finding suggests that AS was not used in most cases, although ACTUR records do not have a field for this 
designation. Furthermore, the database would not detect whether the three untreated patients were subsequently treated at a non-MTF.

One of the primary concerns with a clinical diagnosis of very-low-risk disease is the potential for tumour under-grading or under-staging. The treated cohort of 78 included 72 (92\%) who chose RP; complete pathological examination results were evaluable in 57. Using the Resnick et al. [16] criteria, 86\% (49/57) had favourable pathology (one case of pT0), and 14\% (eight of 57) were upgraded or upstaged (Figure 2). Of those eight cases, two tumours were non-organ confined (pT3a), five had $>10 \%$ gland involvement, and one had a secondary Gleason 4 pattern.

\section{Discussion}

In the present retrospective study, nearly half of PSA screen-detected prostate cancer in DoD servicemen aged $\leq 55$ years were classified as very low risk. This represents a sizable cohort of patients who would be eligible for AS. Indeed, extrapolating that result to the 1605 servicemen diagnosed with PSA screen-detected tumours since 2002, when AS was first described [17], shows that 754 could have been eligible for AS. Nevertheless, > 95\% of the men in the present cohort were treated. Of note, among the tumours treated with RP, > 85\% carried a favourable pathology designation. Thus, at least with the benefit of hindsight, this sizable subset of men with very-low-risk prostate cancer with corresponding favourable pathology may benefit from alternatives to prompt therapy. Nevertheless, the limitations of AS, especially for a younger cohort of men, deserves discussion. In a recent study [18], albeit with less stringent enrolment criteria, 10-year PSA-recurrence for men on AS was $44 \%$ raising the question of missed opportunity for cure.

A 2008 publication by Barocas et al. [19], who used the Cancer of the Prostate Strategic Urologic Research Endeavor (CaPSURE) database, reported that $9 \%$ of men with very-lowrisk disease selected AS, but that study was conducted in an older population (mean age, 64.4 years). Indeed, in that study, older age (> 74 years) was the only demographic predictor of AS. A more recent CaPSURE study [6] showed that among men diagnosed with prostate cancer aged $\leq 55$ years, $65 \%$ had low-risk disease, according to the Cancer of the Prostate Risk Assessment (CAPRA) scale and only $2 \%$ opted for AS. However, importantly, the present study differed by using the more stringent entry criteria advocated for younger patients with prostate cancer owing to their greater relative longevity [11].

Unfortunately, the number of men opting for AS is extremely low [7], probably for several reasons. First and foremost, the clinical criteria that define very-low-risk disease are imprecise, and some tumours are upgraded and/or upstaged at RP, albeit in a study of older men [20]. Nevertheless, it is important to distinguish between disease progression and sampling error: 'disease progression' evident within 2 years is widely regarded as attributable to biopsy sampling error because even with an extended biopsy scheme, $<1 \%$ of the prostate is sampled [21]. On the other hand, one could argue that scheduled follow-up biopsies as part of AS would catch a portion of such cases. It is interesting that the present study contained a smaller fraction (14\%) of upgraded/upstaged tumours than the $29 \%$ cited in another report [22], or the $31 \%$ for an older cohort of men [23] who fulfilled the Epstein criteria for very-low-risk disease. It could be that this difference reflects different criteria for defining favourable disease $[3,16,23]$. However, it should be emphasised that there are no absolute criteria for defining favourable disease. For example, a recent paper [24] revised the index tumour volume parameter used initially [3] from 0.5 to $<1.5 \mathrm{~mL}$.

A second reason for low AS participation is the fear associated with a cancer diagnosis. No matter that a tumour is low volume and Gleason $\leq 6$, the mere mention of 'cancer' evokes a 
reflexive decision for treatment [25]. One recent editorial even suggested adoption of the phrase 'indolent lesions of epithelial origin' [25] instead of 'cancer', although medico-legal considerations make this unlikely.

Third, patients' beliefs and perceptions, in the absence of scientific foundation, bias them toward intervention. Men with localised prostate cancer tend to underestimate their life expectancy without treatment, while overestimating the curative and survival benefits of treatment [26]. Fourth, the wives of young men generally favour surgery for their spouses [27]. Fifth, studies have indicated that younger men are less likely than older men to have organ-confined disease [28], although this is controversial, with some authors reporting favourable clinicopathological features associated with younger age [29].

From the clinician's perspective, treatment selection correlates with medical specialty [30]; thus, most men who consult with a urologist opt for RP [31]. Patients treated at most of the 12 MTFs in the present study consulted solely with a urologist, which may have biased them toward surgical intervention. A second issue is that clinicians may be reluctant to recommend young men for AS for fear of higher rate of progression over time [31]. Finally, AS is labour intensive for both patients and clinicians.

Although all of these reasons bias men toward the option of treatment, it is unlikely that financial disincentives and/or medicolegal concerns contribute to the high rate of surgery in the present DoD study population. Clinician reimbursement rates are not based on patient volume, and litigation liability by active-duty physicians is less a concern because of DoD policies concerning malpractice lawsuits.

The present study had some limitations. First, the population size is modest. Second, DoD personnel differ from their civilian counterparts as to their 'fitness for duty'. Choosing AS may be potentially disqualifying for worldwide deployability or continued service, and these factors may influence the individual to pursue treatment. Third, the criteria we used for defining favourable pathology have not been validated; however, it is noteworthy that neither has the more commonly used parameter set, which differs from ours only in using dominant tumour volume instead of the percentage of prostate gland involvement [3,16]. Finally, we had no data on family history of prostate cancer, which could affect treatment decision-making.

The present study indicates that a sizable cohort of young men diagnosed with PSA screendetected prostate cancer is eligible for AS but nevertheless opts for treatment. Toward increasing participation in AS, our work emphasises the need for well-designed outcome studies that demonstrate the viability of AS in this patient population, new biomolecular markers, to increase the accuracy of predicting which tumours carry favourable pathology, and for behavioural science studies, to identify psychosocial factors associated with treatment decision-making.

\section{Acknowledgments}

Funding

Supported in part by a National Institutes of Health/National Center for Research Resources Clinical and Translational Science Award grant UL1 RR024148, awarded to D.D.B., and in part by the National Institutes of Health through MD Anderson's Cancer Center Support Grant, 5 P30 CA016672.

\section{Abbreviations}

ACTUR Automated Central Tumor Registry 
active surveillance

CaPSURE Prostate Strategic Urologic Research Endeavor

DoD

Department of Defence

MTF

military treatment facility

\section{References}

1. Gosselaar C, Roobol MJ, Schroder FH. Prevalence and characteristics of screen-detected prostate carcinomas at low prostate-specific antigen levels: aggressive or insignificant? BJU Int. 2005; 95:231. [PubMed: 15667646]

2. Dall'Era MA, Konety BR. Active surveillance for low-risk prostate cancer: selection of patients and predictors of progression. Nat Clin Pract. 2008; 5:277-283.

3. Epstein JI, Walsh PC, Carmichael M, Brendler CB. Pathologic and clinical findings to predict tumor extent of nonpalpable (Stage T1c) prostate cancer. JAMA. 1994; 271:368. [PubMed: 7506797]

4. Draisma G, Etzioni R, Tsodikov A, et al. Lead time and overdiagnosis in prostate-specific antigen screening: importance of methods and context. J Natl Cancer Inst. 2009; 101:374-383374. [PubMed: 19276453]

5. Welch HG, Albertsen PC. Prostate cancer diagnosis and treatment after the introduction of prostatespecific antigen screening: 1986-2005. J Natl Cancer Inst. 2009; 101:1325-9. [PubMed: 19720969]

6. Bechis SK, Carroll PR, Cooperberg MR. Impact of age at diagnosis on prostate cancer treatment and survival. J Clin Oncol. 2011; 29:235-241. [PubMed: 21135285]

7. Cooperberg MR, Broering JM, Carroll PR. Time trends and local variation in primary treatment of localized prostate cancer. J Clin Oncol. 2010; 28:1117-1123. [PubMed: 20124165]

8. Barry MJ, Gallagher PM, Skinner JS, Fowler FJ. Adverse effects of robotic-assisted laparoscopic versus open retropubic radical prostatectomy among a nationwide random sample of Medicare-age men. J Clin Invest. 2012; 30:513-518.

9. Vickers AJ, Bianco FJ, Serio AM, et al. The surgical learning curve for prostate cancer control after radical prostatectomy. J Natl Cancer Inst. 2007; 99:1171-1177. [PubMed: 17652279]

10. Warlick C, Trock BJ, Landis P, Epstein JI, Ballentine-Carter H. Delayed versus immediate surgical interventions and prostate cancer outcome. J Natl Cancer Inst. 2006; 98:355-357. [PubMed: 16507832]

11. Klotz LH. Active Surveillance for prostate cancer: A Review. Curr Urol Rep. 2010; 11:165-171. [PubMed: 20425623]

12. Corcoran AT, Peele PB, Benoit RM. Cost comparison between watchful waiting with active surveillance and active treatment of clinically localized prostate cancer. Urology. 2010; 76:703709. [PubMed: 20381846]

13. Hayes JH, Ollendorf DA, Pearson SD, et al. Active surveillance compared with initial treatment for men with low-risk prostate cancer. JAMA. 2010; 304:2373-2380. [PubMed: 21119084]

14. Rogers D, Boyd DD, Fox EE, et al. Prostate cancer incidence in USAF Officers: Aviators compared with non-aviators. Aviat Space Environ Med. 2011; 82:1067-1070. [PubMed: 22097644]

15. Ramsey SD, Zeliadt SB, Fedorenko CR, et al. Patient preferences an urologist recommendations among local-stage prostate cancer patients who present for initial consulation and second opinions. World J Urol. 2010; 29:3-9. [PubMed: 20959991]

16. Resnick MJ, Lee DJ, Magerfleisch L, Vanarsdalen KN, Tomaszewski JE, Wein AJ, et al. Repeat prostate biopsy and the incremental risk of clinically insignificant prostate cancer. Urology. 2011; 77:548-552. [PubMed: 21215436]

17. Lawrentschuk N, Klotz LH. Active surveillance for low-risk prostate cancer: an update. Nat Rev Urol. 2011; 8:312-320. [PubMed: 21519351] 
18. Kane CJ, Im R, Amling CL, et al. Outcomes after radical prostatectomy among men who are candidates for active surveillance: results from the SEARCH database. Urology. 2010; 76:695700. [PubMed: 20394969]

19. Barocas DA, Cowan JE, Smith JA, Carroll PR. What percentage of patients with newly diagnosed carcinoma of the prostate are candidates for surveillance? An analysis of the CaPSURE database. J Urol. 2008; 180:1330-1335. [PubMed: 18707731]

20. Mullins JK, Han M, Pierorazio PM, Partin AW. Radical prostatectomy outcome in men 65 years old or older with low risk prostate cancer. J Urol. 2012; 187:1620-1625. [PubMed: 22425079]

21. Trpkov K, Yilmaz A, Bismar TA, Montironi R. "Insignificant” prostate cancer on prostatectomy and cystoprostatectomy: variation on a theme "low-volume/low-grade" prostate cancer? BJU Int. 2010; 106:304-315. [PubMed: 20653654]

22. Bul M, Zhu X, Rannikko A, et al. Radical prostatectomy for low-risk prostate cancer following initial active surveillance: results from a prospective observational study. Eur Urol. 2012; 62:195200. [PubMed: 22342775]

23. Seiler D, Randazzo M, Klotz L, et al. Pathological stage distribution in patients treated with radical prostatectomy reflecting the need for protocol-based active surveillance: results from a contemporary European patient cohort. BJU Int. 2011; 110:195-200. [PubMed: 22093744]

24. Wolters T, Roobol M, van Leewen PJ, et al. A critical analysis of the tumor volume threshold for clinically insignifiicant prostate cancer usign a data set of a randomized screening trial. J Urol. 2011; 185:121-125. [PubMed: 21074212]

25. Cooperberg MR, Carroll PR, Klotz LH. Active surveillance for prostate cancer: progress and promise. J Clin Oncol. 2011; 29:3669-3676. [PubMed: 21825257]

26. Mohan R, Beydoun H, Barnes-Ely ML, et al. Patients survival expectations before localized prostate cancer treatment by treatment status. J Am Board Fam Med. 2009; 22:247-256. [PubMed: 19429730]

27. Davison BJ, Oliffe JL, Pickles T, Mroz L. Factors influencing men undertaking active surveillance for the management of low-risk prostate cancer. Oncol Nurs Forum. 2009; 36:89-96. [PubMed: 19136342]

28. Lin DW, Porter M, Montgomery B. Treatment and survival outcomes in young men diagnosed with prostate cancer: a population based cohort study. Cancer. 2009; 115:2863-2871. [PubMed: 19466697]

29. Parker PM, Rice KR, Sterbis JR, et al. Prostate cancer in men less than the age of 50: a comparison of race and outcomes. Urology. 2011; 78:110-115. [PubMed: 21397300]

30. Gorin MA, Soloway CT, Eldefrawy A, Soloway MS. Factors that influence patient enrollment in active surveillance for low-risk prostate cancer. Urology. 2011; 77:588-591. [PubMed: 21215429]

31. Sidana A, Hernandez DJ, Feng Z, et al. Treatment decision-making for localized prostate cancer: what younger men choose and why. Prostate. 2012; 75:58-64. [PubMed: 21520163] 
What's known on the subject? and What does the study add?

Little is known as to the potential for over-treatment of young men diagnosed with prostate cancer.

We show that for men aged $\leq 55$ years with PSA screen-detected disease, $45 \%$ of the tumours are classified as very low risk and $85 \%$ of these have favourable pathology, yet most are actively treated. These findings raise the spectre of over-treatment for a group of men likely to be effected by treatment side-effects. 


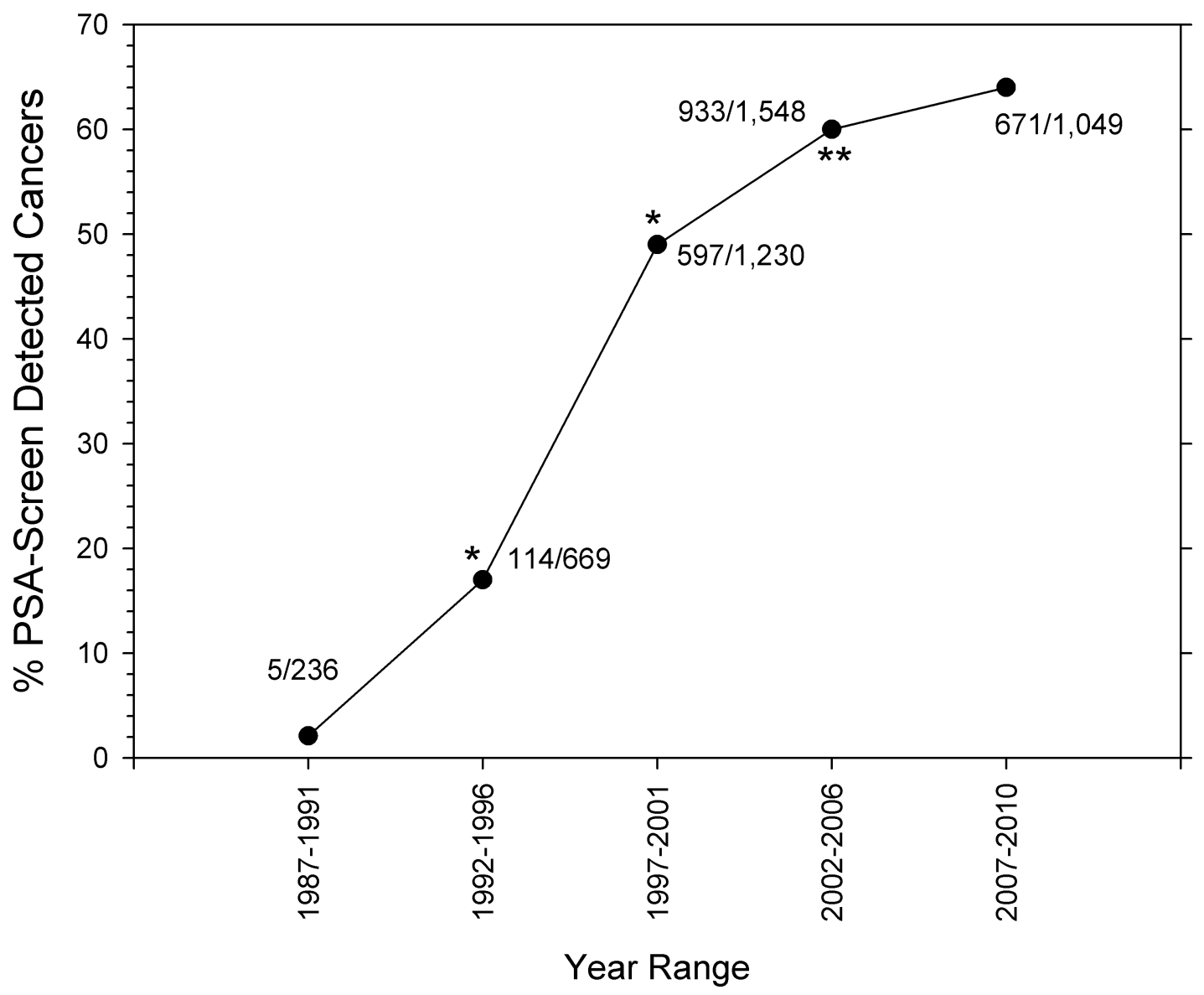

Figure 1.

Increasing rates of PSA screen-detected prostate cancer in DoD personnel. ACTUR was queried for men aged $\leq 55$ years who had been diagnosed with PSA screen-detected disease (cT1c) over the indicated periods. The denominator represents all prostate cancer cases diagnosed ( $\leq 55$ years) for the corresponding periods. For each point, the numerator/ denominator cases are indicated. Statistical analysis was performed using the chi-squared test relative to the prior time period. $* P<0.001$. 


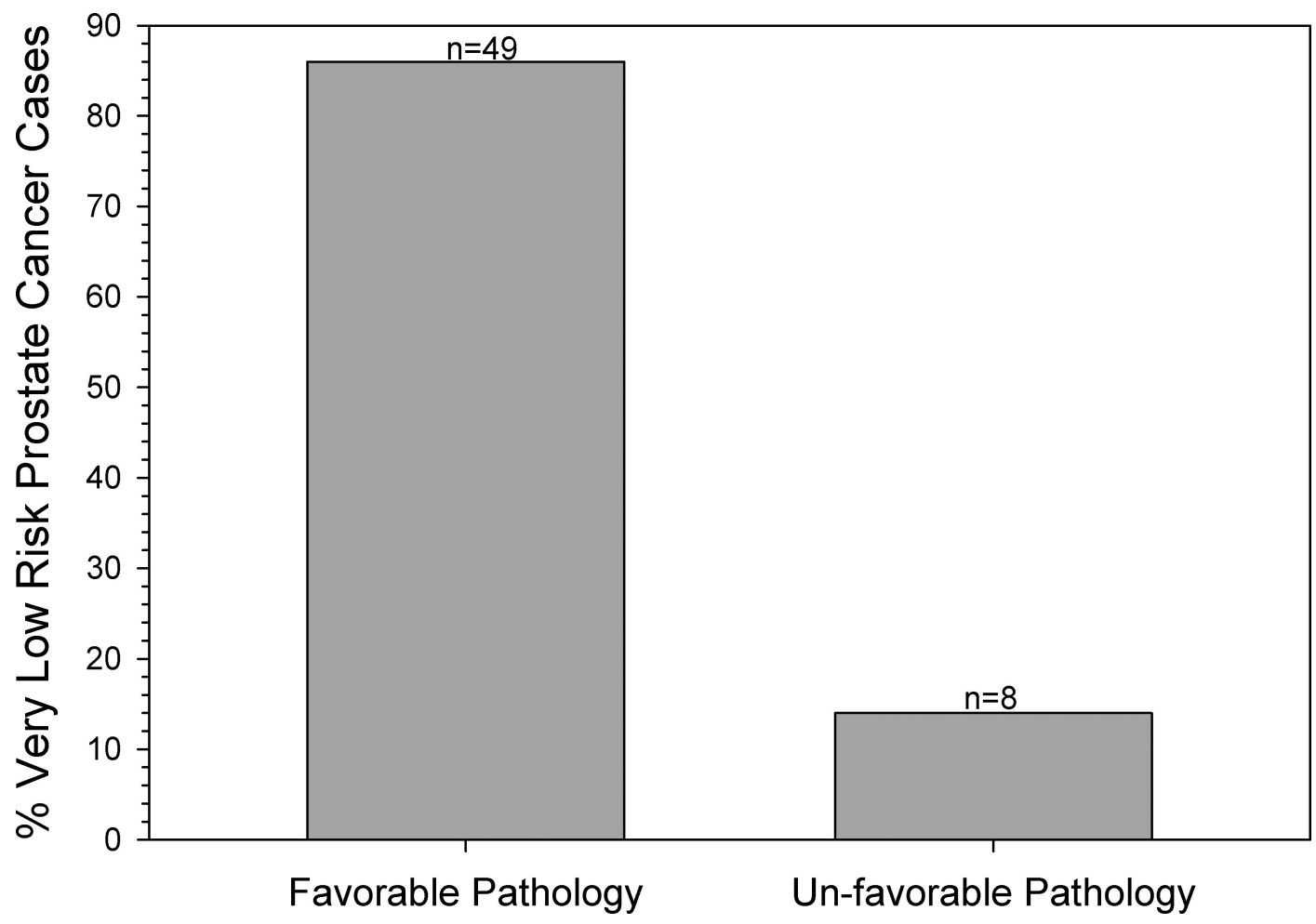

Figure 2.

Tumours in men diagnosed with very-low-risk disease categorised by pathology status. Tumours in men diagnosed aged $\leq 55$ years with very-low-risk disease and who chose RP were pathologically staged. Favourable disease was classified as organ-confined disease (i.e., no extracapsular extension, no seminal vesicle involvement, negative lymph nodes) with $<10 \%$ involvement of the prostate and Gleason score $\leq 6$ (with no pattern 4 ). Tumours not satisfying any of these criteria were categorised as having unfavourable pathology. 


\section{Table 1}

Population and tumour characteristics of PSA screen-detected prostate cancer diagnosed in DoD servicemen aged $\leq 55$ years

\begin{tabular}{|c|c|}
\hline Characteristic & Value \\
\hline No. of patients & 174 \\
\hline Mean (median; range) age (years) & $49.8(50 ; 36-55)$ \\
\hline \multicolumn{2}{|l|}{ Race, n (\%): } \\
\hline White & $100(57)$ \\
\hline Black & $59(34)$ \\
\hline Other/unknown & $15(9)$ \\
\hline Mean (median; range) PSA density at diagnosis, $\mathrm{ng} / \mathrm{mL} / \mathrm{g}$ & $0.16(0.13 ; 0.02-0.91)$ \\
\hline Mean (median; range) total no. of biopsy cores & $12(12 ; 3-26)$ \\
\hline Mean (median; range) no. of positive biopsy cores Mean & $2(2 ; 1-14)$ \\
\hline \multicolumn{2}{|l|}{ Maximum tumour involvement in biopsy cores, $\mathrm{n}(\%)$} \\
\hline$\leq 10$ & $98(56)$ \\
\hline $11-25$ & $38(22)$ \\
\hline $26-50$ & $17(10)$ \\
\hline $51-75$ & $14(8)$ \\
\hline $76-100$ & $7(4)$ \\
\hline Mean (median; range) Gleason score of biopsy specimen & $6(6 ; 5-7)$ \\
\hline \multicolumn{2}{|l|}{ Biopsy Gleason score, $\mathrm{n}(\%)$} \\
\hline 5 & $2(1)$ \\
\hline 6 & $165(95)$ \\
\hline 7 & $7(4)$ \\
\hline
\end{tabular}

